- OH group attached to the $\beta$-carbon atom greatly reduced the nicotine-like action.

J. H. BurN

M. F. CUTHBERT

Research Laboratories,

R. WIEN

May and Baker, Ltd.,

Dagenham, Essex.

' Barger, G., and Dale, H. H., J. Physiol. (Lond.), 41, 19 (1910).

\section{Skin Reaction to Intradermal Injection of Rare Earths}

'THE availability of highly purifiod rare earths, elements 21 and 58-71, has stimulated interest in their chemical and physical properties ${ }^{1}$. Haley et al..$^{2-6}$ have examined their biological effects and reported that although they can produce non-specific liver damage they exert their greatest toxicity on the ocular and dermal tissues. However, even this damage can be repaired with time and results in no permanent injury. Recently, it was observed that the intradermal injection in guinea pigs of $0.05 \mathrm{ml}$. aqueous solutions of $1 \times 10^{4}-1 \times 10^{6}$ concentrations of praseodymium, neodymium, europium, dysprosium, holmium, erbium or lutetium chlorides resulted in the formation of $2 \cdot \mathrm{mm}$ diameter nodules containing crystalline deposits (Fig. 1). Observation for periods of 45 days showed no decrease in nodule size or any resorption of the crystalline deposits.

Differential staining of histological sections with Dominici, Prussian blue and von Kossa stains indicated the presence of histiocytes and foreign body giant cells surrounding the crystals with fibroblasts and granulation
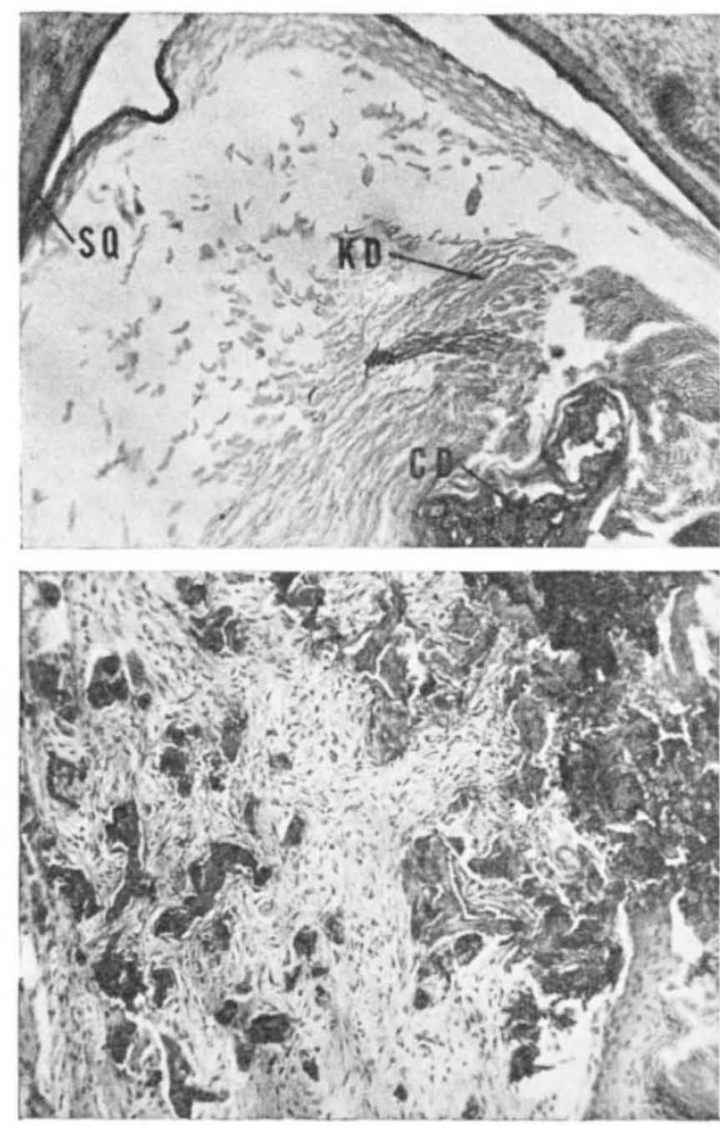

Fig. 1. Dermal reaction to injection of $0.05 \mathrm{ml}$. of $10^{6}$ lutetium chloride in guinea pigs. Upper photomicrograph illustrates presence of keratotic debris $(K D)$, stratified squamous epithelium $(S Q)$ and crystallin deposits $(C D)$. Lower photomicrograph illustrates foreign body giant cells in lower right-hand corner of upper photomicrograph tissue extending into the area. There was an indication of calcium but no iron in the crystals. Considering the total amount of rare earth injected, 0.05-5 $\mu \mathrm{g}$, further analysis was not possible to establish the exact composition of the crystals. Furthermore, analytic procedures for the rare earths are non-specific and the presence of other ions would interfere to the extent of negating a more complete analysis. Of prime importance is the tissue reaction to such low levels of element and its implication to industrial prevention of injury during chemical processing. A re-evaluation of the other members of the series is being undertaken to determine whether or not they also can induce such changes in tissue at the same concentrations.

This work was supported by contract $A T(04-1) G E N-12$ between the Atomic Energy Commission and the University of California.

\section{Thomas J. Haley}

HaRVey C. UPham

Laboratory of Nuclear Medicine and Radiation Biology,

Department of Biophysics and Nuclear Medicine,

University of California at Los Angeles.

1 ppedding, F. H., and Daane, A. H. The Rare Earths (John Wiley and Sons, Inc., New York and London, 1961).

${ }^{2}$ Haley, T. J., Raymond, K., Komesu, N., and Upham, H. C., Brit. J. Pharmacol, 17,526 (1961).

${ }^{3}$ Haley, T. J., Komesu, N., Mavis, L., Flesher, A. M., and Cawthorne, J., Fed. Proc., 21, 449 (1962).

‘ Haley, T. J., Komesu, N., Mavis, L., Cawthorne, J., and Upham, H. C. J. Pharm. Sci., 51, 1043 (1962).

${ }^{5}$ Haley, T. J., Komesu, N., Flesher, A. M., Mavis, L., Cawthorne, J., and Upham, H. C., Toxicol. App. Pharmacol., 5, 427 (1963).

- Haley, T. J., and Komesu, N., Fed. Proc., 22, 189 (1963).

\section{Some Biological Properties of 'Ibufenac', a New Anti-rheumatic Drug}

For some years we have been investigating the biological properties of substituted phenylalkanoic and phenoxyalkanoic acids and related compounds. We wish to describe briefly the properties of one of these, 'Ibufenac', which Chalmers and Duthie have recently shown to be effective in the treatment of rheumatoid arthritis ${ }^{1}$

'Ibufenac' (British Pharmacopœia Commission approved name) is 4-isobutylphenylacetic acid, a colourless crystalline solid, melting-point $85^{\circ}-87^{\circ} \mathrm{C}$. It is relatively insoluble in water, but readily soluble in most organic solvents.

This compound has been tested by the oral route in a number of different anti-inflammatory and analgesic tests, and the results obtained in some of these are reported here. The anti-inflammatory activity of 'Ibufenac', as assessed by an ultra-violet erythema test in guinea pigs $^{2}$, is $2-4$ times that of aspirin. Its analgesic activity, measured by a modification of the method described by Randall and Selitto ${ }^{3}$, is also $2-4$ times that of aspirin. The antipyretic activity is approximately 4 times that of aspirin when measured over a 4-h period in the yeast-fevered rat. The minimal effective dose of 'Ibufenac' for redueing thurfyl nicotinate ('Trafuril') erythema in man is $960 \mathrm{mg}$. The compound exhibits no glucocorticoid activity when tested in the mouse by a modification of the method described by Silber ${ }^{4}$.

The acute oral $L D_{50}$ in mice is approximately 1,800 $\mathrm{mg} / \mathrm{kg}$. Rats given $250 \mathrm{mg} / \mathrm{kg}$ daily for 6 months remained in good health and the only abnormality at necropsy was slight enlargement of the liver, kidneys and adrenal glands, which was reversible. Dogs were given daily oral doses of 40,80 and $160 \mathrm{mg} / \mathrm{kg}$ for 6 months; some animals receiving 80 and $160 \mathrm{mg} / \mathrm{kg}$ showed simple renal hypertrophy, but kidney function was normal and there was no histological abnormality; gastric damage was found only at the highest dose. 